\title{
$O$ papel das professoras no incentivo à carreira de Computação para meninas no Ensino Fundamental
}

\author{
Bruna Oenning Amador ${ }^{1}$, Patricia Abe Turato ${ }^{1}$, Mayara Dal Vesco Hoger ${ }^{1}$, Lara \\ Morgado da Silva Santos ${ }^{1}$, Silvia Amélia Bim ${ }^{1}$, Rita Cristina Galarraga Berardi ${ }^{1}$
}

${ }^{1}$ Universidade Tecnológica Federal do Paraná (UTFPR)

\author{
Curitiba - PR - Brasil \\ \{brunaamador, patriciaturato, mayarahoger, \\ laramorgado\}@alunos.utfpr.edu.br, \{sabim, ritaberardi\}@utfpr.edu.br
}

\begin{abstract}
Many actions have been accomplished with the aim of attracting more girls to Computing, since workshops with middle school students up to actions to keep them in college, once they already decided their career. In Brazil, taking into account the more than 100 associated projects of Meninas Digitais, the vast majority of them focus their actions on the female students. However, projects that focus on the middle school teachers also can be allied to the cause. For this purpose, the teachers need to know more about the computing career, as to what the professionals do and the field of activity they can work on. Then, they can help spread this knowledge to the students. This article emphasizes the demand for projects that can assist the teachers, since it was possible to identify stereotypes and important gaps in Computing concepts.
\end{abstract}

Resumo. Muitas ações têm sido realizadas com o intuito de atrair mais meninas para a Computação, que vão desde oficinas com alunas do Ensino Fundamental até ações para mantê-las nas universidades uma vez que elas escolhem essa carreira. No Brasil, considerando os mais de 100 projetos parceiros do Meninas Digitais, a grande maioria destes têm as estudantes como foco das ações. No entanto, projetos com foco nas professoras do Ensino Fundamental também podem ser aliados à causa. Para isso, essas professoras precisam conhecer mais sobre as carreiras na Computação, o que fazem os profissionais, qual o perfil de atividade e, assim, auxiliar na divulgação da área. Este artigo evidencia essa demanda por projetos que auxiliem as professoras, uma vez que foi possível identificar visões estereotipadas e lacunas importantes em conceitos sobre a área de Computação como um todo.

\section{Introdução}

A falta de representatividade feminina no ramo da tecnologia é algo muito presente nas discussões atuais. Segundo as estatísticas de Educação Superior em Computação da Sociedade Brasileira de Computação (SBC) [SBC 2019], enquanto o número de matrículas do gênero masculino chega em média a 350.000 por ano, o público feminino alcança apenas a marca de 50.000. Além disso, mais de 45.000 homens concluem os estudos a cada ano e somente cerca de 5.000 mulheres conseguem finalizá-los, 
mostrando que o espaço que as mulheres brasileiras ocupam nos cursos de Computação ainda é pequeno. A falta de credibilidade, as situações de humilhação, a objetificação e o preconceito que as mulheres que optam por desafiar as estatísticas podem sofrer são alguns dos empecilhos na luta por esse espaço na tecnologia [Semis and Monteiro 2016].

A desconstrução dos estereótipos criados de que "mulher não sabe programar" e que "Tecnologia da Informação (TI) é coisa de homem", desde a infância e dentro de sala de aula, pode ser uma boa estratégia para conquistar mais meninas e estimulá-las a ingressar na área de tecnologia. As próprias alunas relatam que o machismo, a comparação da capacidade com a dos homens, a sensação de isolamento devido a área ser predominantemente masculina e a ideia imposta de que Computação é coisa de homem, são alguns dos fatores que dificultam o ingresso de mulheres na área [Aires et al. 2018].

Por esse motivo, instruir as professoras de forma correta e clara a respeito de como introduzir pensamento computacional dentro de sala de aula e, assim, esclarecer as questões relacionadas à profissão pode ser um fator essencial para atrair, gradativamente, aquelas que muitas vezes nem pensariam em seguir uma carreira no campo da tecnologia, como será discutido na Seção 2.

Existem, no momento atual, vários relatos de experiências em projetos que trabalham o uso do pensamento computacional ou do raciocínio computacional com alunos da Educação Básica. No entanto, os projetos e os relatos que dão visibilidade às professoras não são tão comuns [Matos et al. 2021].

À vista disto, foi ministrada, pelo projeto TIChers ${ }^{1}$, uma oficina de Banco de Dados para professoras da Educação Básica, com o propósito de introduzir às docentes a temática sobre banco de dados e pensamento computacional, e, a partir da correlação dos assuntos técnicos com aplicações práticas no uso de dados, incentivá-las a se tornarem aliadas na disseminação da Computação de forma correta perante seus estudantes, atraindo mais meninas para a área. Forma correta, aqui, entende-se por uma disseminação livre de estereótipos e mais abrangente, como explicar que a carreira de computação não abrange somente atividades relacionadas à programação. Por meio desta oficina, foi possível também coletar dados para identificar a percepção das professoras sobre a carreira e o quanto a oficina auxiliou na mudança de percepções limitadas.

Assim, o objetivo deste artigo é discutir o papel das professoras da Educação Básica para atrair meninas para a Computação a partir da exploração dos dados de percepção das docentes.

\section{Papel das professoras ${ }^{2}$ na influência das carreiras}

A discussão sobre o papel das professoras, quando o assunto é influência nas carreiras, ainda é pouco abordada. Portanto, as referências são escassas e, quando encontradas, os

\footnotetext{
${ }^{1}$ Projeto parceiro do Programa Meninas Digitais da SBC.

${ }^{2} \mathrm{O}$ gênero feminino é utilizado ao longo do artigo para se referir ao grupo de docentes, visto que as professoras representam $97,6 \%$ das participantes das oficinas, como abordado posteriormente na seção 4, e a maioria das professoras no Brasil são mulheres [Brasil. INEP, 2021].
} 
resultados para a discussão consideram apenas os estudantes do Ensino Médio. Vale ressaltar que é necessário provocar novas discussões com enfoque nessa temática.

Segundo a pesquisa feita por [Buscacio and Soares 2017], a opinião de docentes, principalmente do Ensino Médio, é relevante na escolha da profissão. No entanto, de modo geral, a família funciona como uma referência primária para os estudantes.

Do mesmo modo, a pesquisa feita por [Neto et al. 2016], com estudantes do Ensino Médio, mostra que a influência da professora sobre as escolhas dos estudantes é mínima, e que, apesar de se encontrar numa posição em que a professora tem condições de influenciar, já que exerce um papel de educadora, ela não aproveita essa situação para motivar seus alunos.

Pode-se notar que a influência das professoras em estudantes do Ensino Médio, apesar de existente, ainda é tímida. Dessa forma, ações voltadas para as alunas do Ensino Fundamental podem ter um efeito mais produtivo do que para as do Ensino Médio, onde a maioria já está com a decisão tomada [Holanda et al. 2017], uma vez que todas as pessoas começam a formular decisões vocacionais desde a infância [Stanley and Mangiesi 1984 apud Herr and Cramer 1996 apud Ferreira et al. 2009]. Além disso, a escola e as vivências que nela têm lugar podem facilitar aprendizagens significativas, capazes de influenciar o processo de orientação vocacional dos indivíduos.

Por fim, o estudo de [Martins et al. 2019], trouxe como um dos fatores que atraem meninas para cursos da área de TI "Despertar a curiosidade pela área em meninas desde a infância", mostrando novamente a necessidade de trabalhar e incentivar as estudantes mais novas e, também, quem atua diretamente com elas, atraindo cada vez mais meninas para a Computação.

\section{Metodologia}

Os dados utilizados neste artigo contemplam respostas de professoras do Ensino Básico da cidade de Curitiba, no Paraná, que fazem parte dos programas de formação da prefeitura da capital. As docentes participaram de uma oficina sobre Banco de Dados, a qual foi ministrada para dois grupos distintos de professoras, com 19 participantes no primeiro grupo e 23 no segundo, totalizando 42 participantes. Os conteúdos abordados nesta oficina foram os mesmos de uma oficina realizada com alunas do Ensino Médio [Berardi et al. 2019], a qual foi adaptada para docentes da Educação Básica.

O tema central da oficina era mostrar como conceitos de banco de dados podem ser trabalhados com temáticas atuais e, para isso, trabalhou-se de forma desplugada como funciona a organização de dados em um banco de dados. Dessa maneira, para compreender se a oficina mudou a visão das professoras em relação à Computação e fazer a análise detalhada desses resultados, foi pedido que respondessem um questionário online ${ }^{3}$ no início e outro no final da oficina.

No início do primeiro questionário, foram realizadas perguntas de informações mais pessoais, como idade e em que área lecionam, a fim de traçar o perfil das professoras participantes. Após estas, estavam perguntas que visavam compreender o que as professoras entendiam por Computação e Banco de Dados, como as perguntas

\footnotetext{
${ }^{3}$ Link para questionário inicial bit.ly/2oLebz2 e link para questionário final bit.ly/30JMeVq.
} 
"O que você costuma responder quando é perguntado sobre o que faz alguém que trabalha com TI/Computação?" e "Você já estudou conceitos introdutórios de Computação?". Além disso, foram feitas perguntas discutindo a visão das participantes sobre a questão de gênero na Computação e como elas se sentiam ao falar sobre a área com seus estudantes.

O segundo questionário teve o objetivo de entender a visão das docentes em relação à oficina, o que aprenderam com esta e, principalmente, para perceber se a visão delas em relação à Computação mudou, como na questão "A experiência de participar da oficina mudou a sua opinião sobre a Computação como um todo?". Além disso, as participantes foram questionadas sobre como elas se sentiam pós-oficina para falar com seus estudantes sobre Computação, abordado na pergunta "Você se sentiria apta a falar sobre pensamento computacional com seus alunos?".

\section{Análise dos resultados}

Esta seção apresenta os resultados da oficina em 9 subseções em formato de perguntas que auxiliam na discussão sobre o papel das professoras no incentivo à área de Computação por parte das meninas. Foram analisados o perfil das participantes, a percepção das professoras antes e depois da oficina, o momento em que as alunas começam a perguntar sobre carreira, se as professoras podem ajudar na divulgação de TI, a importância das oficinas voltadas para as professoras, a abrangência e efetividade dos cursos/oficinas que as professoras recebem, a visão das professoras sobre as mulheres na Computação e, por fim, a avaliação sobre a iniciativa da SBC de inserir conteúdos de Computação no currículo.

\subsection{Qual o perfil das participantes?}

Traçando o perfil das participantes, o público foi formado, em sua maioria, por professoras, posto que $97,6 \%$ se identificaram com o gênero feminino. Além disso, a faixa etária majoritária está entre 30 e 40 anos, representada por $53,7 \%$ das participantes, seguido pelo intervalo de 40 e 50 anos, com $34,1 \%$.

As professoras, em sua maioria, lecionam somente em rede pública $(97,6 \%)$ e trabalham predominantemente com as disciplinas, considerando que múltiplas respostas poderiam ser selecionadas, Ciências e Tecnologias com 26,7\%, Faróis do Saber $^{4}$ com 13,3\% e Espaço Maker e Matemática com 11,1\% cada.

\subsection{Qual era a percepção das professoras antes da oficina?}

A pergunta "O que você costuma responder quando é perguntado sobre o que faz alguém que trabalha com TI/Computação?" causou bastante divergência. Vale observar que as opções eram respostas fechadas pré-elaboradas no questionário, como mostra a Figura 1. A resposta considerada mais adequada seria "Resolve problemas da sociedade através da tecnologia".

\footnotetext{
${ }^{4}$ Faróis do Saber são bibliotecas de bairro que promovem atividades extracurriculares para alunos da Rede Municipal de Ensino de Curitiba e outras atividades para a comunidade. Os Faróis também possuem um espaço maker, onde são desenvolvidos projetos utilizando baixa tecnologia, no qual os estudantes aprendem a prototipar, codificar, colaborar em grupos, entre outras habilidades desenvolvidas.
} 


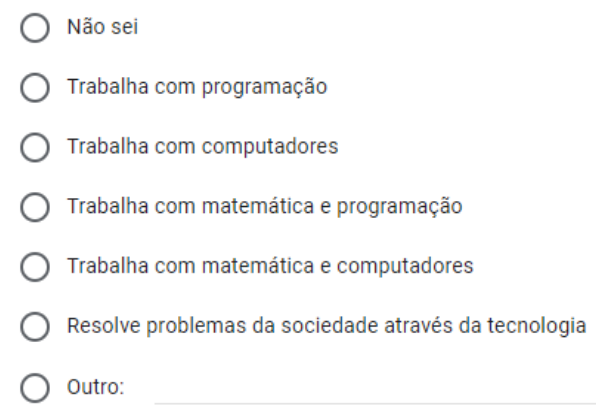
Figura 1. Respostas para a pergunta "O que você costuma responder quando é
perguntado sobre o que faz alguém que trabalha com TI/Computação?".

Do total de participantes, 53,7\% informaram respostas focadas somente a uma área da Computação - como a programação - as quais podem refletir estereótipos como "Trabalha com computadores" que alcançou 24,4\% e "Trabalha com programação" com 19,5\%. É perceptível que a matemática é considerada em algumas respostas como essencial para o estudo de Computação e a questão também é respondida com "Manutenção de computadores". Essa questão mostra uma visão bastante limitada e focada apenas em computadores e em programação, o que muitas vezes não é tão atrativo caso a menina não saiba o que de fato é feito quando se programa, como resolver problemas de diversas áreas. Além disso, a questão obteve 36,6\% para "Resolve problemas da sociedade através da tecnologia", que seria o esperado entre as opções, e 9,8\% não sabiam responder ou colocaram respostas vagas como "Procuro fazê-los pesquisar" e "Todos".

\subsection{A percepção das professoras mudou após a oficina?}

O feedback foi 97,5\% positivo, alcançando comentários como "Agregou conhecimento e pensei na tecnologia de outra forma", "Muito boa. Ajudou-me a entender quem trabalha na área e a ter mais interesse pela área", "Muitíssimo relevante" e "Me fez ter um novo olhar sobre a Computação, estou apaixonada". Também obteve 67,5\% em "Sim, totalmente" e 30\% em "Sim, parcialmente" quando foi perguntado se "Esta oficina mudou sua percepção sobre o que faz quem trabalha com Computação?”.

É importante destacar que a resposta da pergunta "O que você costuma responder quando é perguntado sobre o que faz alguém que trabalha com TI/Computação?', que inicialmente houve divergência, ao final da oficina, $90 \%$ escolheram "Resolve problemas da sociedade através da tecnologia".

\subsection{Quando as alunas começam a perguntar sobre carreira?}

Analisando a pergunta "De qual período é mais comum que alunos perguntem sobre profissões em geral?", é possível concluir que os quartos e quintos anos do Ensino Fundamental foram indicados com $29,2 \%$ e $36,1 \%$, respectivamente, como interessados em escolhas de carreira, seguidos pelos segundos e terceiros anos do Ensino Médio, com $8,3 \%$ cada. Esses dados mostram que a curiosidade por parte dos estudantes em relação às profissões já existe desde o Ensino Fundamental. Dessa forma, logo quando as dúvidas surgirem, é importante que as professoras estejam preparadas para relatar de forma mais próxima possível sobre o que fazem profissionais que trabalham com Computação, pois é uma grande oportunidade para atrair as meninas para a área. 


\subsection{As professoras podem ajudar na divulgação de TI?}

Como discutido na Seção 2, as professoras são aliadas essenciais para divulgar carreiras visto que estão em frequente contato com as estudantes durante o período em que elas tomam a decisão, auxiliando em dúvidas e incentivando sobre qual caminho seguir.

Foi utilizada uma Escala Likert, em que o 1 significava raramente e o 5 muito frequente, para discutir a frequência com que as professoras são questionadas por estudantes sobre profissões em geral. $39 \%$ das participantes afirmaram que são questionadas ocasionalmente sobre o assunto e $22 \%$ das professoras raramente são questionadas. Além disso, a frequência com que as docentes recebem perguntas dos estudantes sobre profissões em geral, é baixa para $22 \%$ das participantes. Já a frequência com que elas são questionadas sobre Computação (TI) é baixa para 34,1\% das professoras, enquanto $26,8 \%$ das docentes são raramente questionadas e essa mesma porcentagem ocorre para as que são ocasionalmente questionadas. Entretanto, mesmo a frequência relatada no questionário sendo predominantemente média e baixa, é necessário que as profissionais estejam preparadas para quando o contato acontecer.

É importante ressaltar que a maioria $(65,9 \%)$ reconhece que a proporção é a mesma entre meninos e meninas com relação a quem mais faz perguntas sobre profissões. Além disso, a porcentagem de professoras que afirmam ser os meninos e ser as meninas é a mesma, indicando que a chance de divulgar a Computação é igual para ambos os sexos.

\subsection{Por que fazer oficinas voltadas para as professoras?}

Muitos projetos atuais sobre Computação acabam voltando suas dinâmicas para as alunas e é importante que existam pessoas as acolhendo e as ajudando. No entanto, as professoras e educadoras têm um papel importante na vida dos jovens, de uma maneira singular acabam influenciando a trajetória de vida e de carreira [Faht 2011]. Dessa forma, as professoras também precisam de suporte para que as ações tenham efeito a longo prazo e, assim, ter uma "divulgação continuada" em sala de aula, visto que o investimento na formação continuada, na pesquisa e na experimentação de novas práticas lhes são úteis não somente para requalificação profissional, mas fundamentalmente para oferta de novos sentidos às profissionais [Matos et al. 2021].

Foi realizada a pergunta "Você se sente encorajado(a) a incentivar seus(suas) alunos(as) a seguirem a área de Computação como profissão?" e, inicialmente, foram obtidos apenas 68,3\% "Com certeza", seguido de 14,6\% dos votos para "Talvez" e 12,2\% "Sim". Após a realização da oficina, os resultados mudaram para 87,5\% "Com certeza" e 12,5\% "Sim", mostrando que ainda há muito a ser ensinado sobre o que profissionais de Computação fazem e que a professora é a agente que irá construir tais conhecimentos com os futuros profissionais, podendo atrair meninas para a área.

Em seguida, questionou-se sobre a experiência de participar da oficina e se ela mudou a opinião das professoras sobre a Computação como um todo. 55\% responderam que "Sim, totalmente" e 37,5\% que "Sim, parcialmente", justificando com respostas como "Sim, pois desmistificou conceitos, ampliou horizontes e facilitou a compreensão do que é realmente computar." e "Que Computação é uma coisa mais simples; não tinha ideia que mulheres 'sofriam' abusos por escolherem esta profissão!". Também vale ressaltar a resposta "Sinto a necessidade de mais treinamentos", que vai de encontro 
com a pergunta "Você se sentiria apta a falar sobre pensamento computacional com seus alunos?", como mostra a Figura 2.

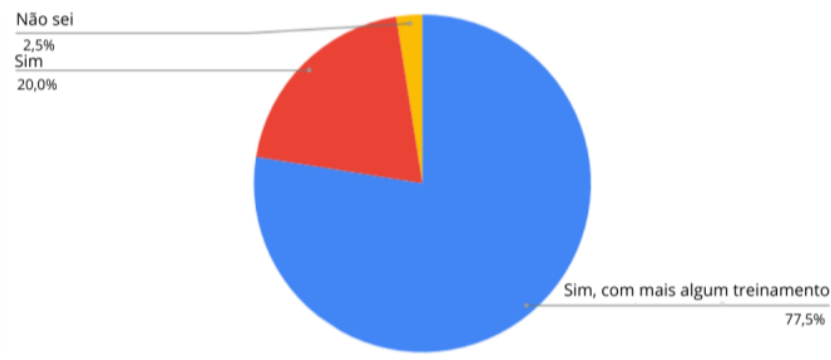

Figura 2. Gráfico das respostas para a pergunta "Você se sentiria apta a falar sobre pensamento computacional com seus alunos?".

É visível que $97,5 \%$ das professoras se sentem aptas a falar sobre pensamento computacional, mas 79,5\% dessas ainda reconhecem a necessidade de algum treinamento, mostrando que é preciso seguir trabalhando a Computação com as docentes.

\subsection{Qual a abrangência e efetividade dos cursos/oficinas que as professoras recebem?}

Mesmo discutindo a importância de oficinas e projetos voltados às professoras, é necessário questionar a abrangência dos conteúdos apresentados para essas profissionais. Foi perguntado no questionário inicial se "Você já estudou conceitos introdutórios de Computação?" e, mesmo com tanta divergência em perguntas introdutórias de Computação e Banco de Dados, muitas já receberam formações anteriores, como é visto na Figura 3.

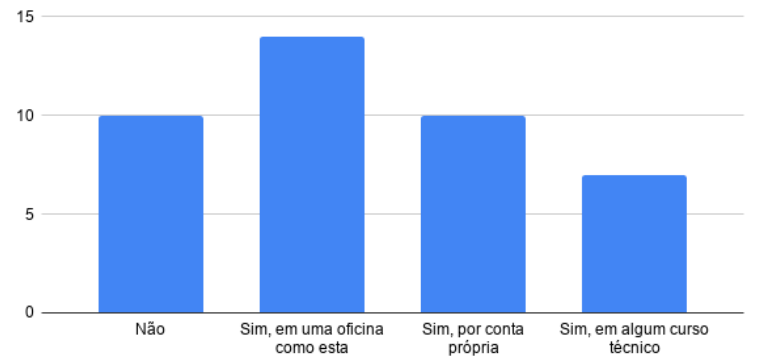

Figura 3. Gráfico das respostas para a pergunta "Você já estudou conceitos introdutórios de Computação?".

Apenas $24,4 \%$ das participantes não tinham nenhum contato prévio com a área, e, dessas, apenas uma colocou a resposta que melhor condiz com o que faz um profissional de TI/Computação, ou seja, "Resolve problemas da sociedade através da tecnologia". Em contrapartida, $75,6 \%$ já tinham conhecimento na área através de oficinas anteriores, cursos técnicos e estudos por conta, e apenas 45,2\% destas responderam conforme o esperado, ou seja, menos da metade das participantes com algum conhecimento prévio. Assim, é visível que o número de acertos foi baixo, mostrando que as professoras têm contato com a Computação, mas que a abrangência e a fixação de conceitos, apesar de muito importantes, não são exploradas com ênfase. Vale ressaltar que a amostra tem um perfil diferenciado, considerando-se que as participantes têm envolvimento com iniciativas da Educação Básica de Curitiba que estimulam a aquisição e a prática de conceitos de Computação e Tecnologia. 
Logo, a falta de abrangência e efetividade de cursos/oficinas, pode resultar na transmissão incorreta ou superficial da informação para estudantes, dando enfoque somente a uma área da Computação, mantendo os estereótipos enraizados. Estudos internacionais no campo da tecnologia indicam a redução da participação de mulheres e associam tal cenário à construção de estereótipos que reforçam essa área como território masculino [Souza 2017], mostrando a importância de dar enfoque sobre o problema.

\subsection{Qual a visão das professoras sobre as mulheres na Computação?}

A pergunta "Você acha que a mulher pode sofrer algum tipo de preconceito ou discriminação por escolher atuar na área de Computação?" obteve respostas bem diversas, como observado na Figura 4.

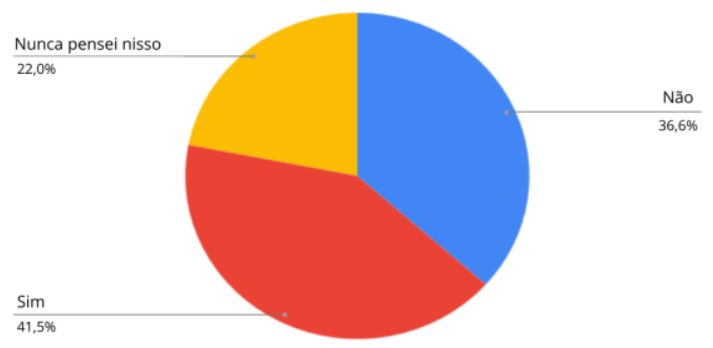

Figura 4. Gráfico das respostas para a pergunta "Você acha que a mulher pode sofrer algum tipo de preconceito ou discriminação por escolher atuar na área de Computação?".

Os preconceitos citados foram "Área culturalmente masculina", "Subestimar a capacidade de raciocínio lógico", "Superioridade social, a mulher não tem capacidade" e, entre eles, "Talvez se sinta isolada em um ambiente que não tenha muitas mulheres. Precisa de mais incentivo em relação aos professores".

Em contrapartida, como resposta para a pergunta "Na sua opinião qual a razão para as meninas não escolherem cursos da área de Computação?”, 61,7\% colocaram "Falta de conhecimento na área", 19,1\% não souberam responder e $8,5 \%$ porque "Não gostam de matemática". É visível como muitas apontam a matemática e a falta de afinidade com a área como fatores, mas muito mais meninas do que meninos perdem o interesse em matemática e ciências após o Ensino Fundamental [of University Women and the Analysis Group 1994], então será que as próprias professoras não carregam estereótipos? E o quanto eles estão impactando negativamente nessas alunas?

Assim, as escolas podem transmitir preconceito de gênero e sinalizam para meninas e meninos o que se espera deles e essas expectativas determinam como eles são tratados, como são ensinados e, em última análise, como são rastreados em caminhos diferentes através de sua escolaridade e até suas carreiras [of University Women and the Analysis Group 1994]. Dessa forma, é de extrema importância trabalhar temáticas como a de mulheres na Computação, visto que os professores têm influência na construção de crenças, representações e valores, particularmente no que diz respeito ao mundo das formações e profissões [Imaginário 1990, 1995].

\subsection{Qual a avaliação sobre a iniciativa da $\mathrm{SBC}$ de inserir conteúdos de Computação no currículo?}

As avaliações das professoras quanto a iniciativa da SBC de inserir conteúdos de Computação no currículo foi muito positiva, recebendo comentários como 
"Fundamental importância", "Relevante, visto que o avanço da tecnologia e a inovação estão ressignificando o modo de pensar." e "Essencial. O país precisa formar cidadãos para o contexto atual que está exigindo imersão imediata nas novas tecnologias, principalmente porque novas profissões irão surgir com os avanços que estão por vir." Ressaltando o comentário de que "A iniciativa é excelente, porém primeiro é necessário capacitar os professores.".

\section{Considerações finais}

É notável que a estratégia de trabalhar diretamente com docentes ainda é incipiente no contexto brasileiro [Bim and Berardi 2020], precisando de projetos que trabalhem a conscientização e formação de docentes da Educação Básica sobre diversos conceitos da Computação, para que possam multiplicar estes conhecimentos.

Em contrapartida, é evidente que a professora, tendo em conta a sua proximidade com os estudantes, é muitas vezes procurada como fonte de apoio para dúvidas e preocupações vocacionais [Ferreira et al. 2009] e que o que é dito pelo profissional pode influenciar na escolha vocacional. Dessa forma, conforme discutido na Seção 2, a professora se torna uma agente muito importante para a disseminação da Computação e, portanto, existe a necessidade de que as docentes trabalhem conceitos de Computação no Ensino Básico, para que as meninas possam ser influenciadas positivamente desde jovens.

Em vista disso, a análise dos resultados, discutida na Seção 4, mostra que as professoras precisam de formação adequada para poder replicar os conhecimentos adquiridos sobre Computação, sendo necessárias as ações voltadas para as docentes, mas com o cuidado de que transmitam conteúdos de maneira clara e didática, não reforçando estereótipos.

Assim, a disseminação dos conceitos de Computação no Ensino Fundamental pelas professoras pode ajudar a incentivar as meninas a seguirem uma carreira na área $\mathrm{e}$ desconstruir a forma como a Computação é vista.

\section{Referências}

Aires, J., Mattos, G., Oliveira, C., Brito, A., Aragão, A., Alves, S., Coelho, T., and Moreira, G. (2018). Barreiras que Impedem a Opção das Meninas pelas Ciências Exatas e Computação: Percepção de Alunas do Ensino Médio. In Anais do XII Women in Information Technology. Porto Alegre: SBC.

Berardi, R., Kozievitch, N., Bim, S. and Auceli, P. (2019). Oficina de Banco de Dados com Aprendizado Cinestésico para Meninas do Ensino Médio. Anais do Workshop de Informática na Escola, 25(1), 345-354.

Bim, S. A., and Berardi, R. C. G. (2020). TIChers - conscientização e formação de docentes da Educação Básica por mais mulheres na Computação. Anais do XIV Women in Information Technology, Cuiabá: SBC, pp.269-273.

Brasil. Instituto Nacional de Estudos e Pesquisas Educacionais Anísio Teixeira (Inep). Censo da Educação Básica 2020: resumo técnico. Brasília, DF: INEP, 2021. 
Buscacio, R. C. Z. and Soares, A. B. (2017). Expectativas sobre o desenvolvimento da carreira em estudantes universitários. Revista Brasileira de Orientação Profissional, 18(1), 69-79.

de Holanda, M., Mourão, R., Ramos, G., de Araújo, A., and Walter, M. (2017). Uma Pesquisa com Alunas do Ensino Fundamental e Médio sobre os Cursos da Área de Computação. Anais do XI Women in Information Technology. Porto Alegre: SBC.

de Souza, T. P. (2017). "A Desigualdade de Gênero no Campo da Tecnologia da Informação”, Seminário Internacional Fazendo Gênero 11 \& 13th Women's Worlds Congress.

Faht, B. H. (2011). Fatores que influenciam a escolha profissional do jovem universitário e sua visão a respeito da orientação profissional. 122 f. Dissertação (Mestrado em Educação) - Universidade do Vale do Itajaí, Itajaí, 2011.

Ferreira, A. F., Nascimento, I. and Fontaine, A. M. (2009). O papel do professor na transmissão de representações acerca de questões vocacionais. Revista Brasileira de Orientação Profissional, 10(2), 43-56.

Imaginário, L. (1990). Desenvolvimento vocacional. Em B. Campos (Org.), Psicologia do desenvolvimento e educação de jovens: Vol. 2. Lisboa: Universidade Aberta.

Imaginário, L. (1995). Reestruturação curricular e orientação escolar e profissional. Noesis, 35, 30-32.

Martins, A., Silva, J., Santos, J., and Rebouças, A. (2019). Fatores que Atraem e Afastam as Meninas de cursos da Área de TI. Anais do XIII Women in Information Technology, (pp. 114-118). Porto Alegre: SBC.

Matos, E., Coutinho, C., Santos, E., dos Santos, J., Azevedo, L., Tavares, G., and Zabot, D. (2021). Desenvolvendo e descobrindo competências no currículo escolar por meio do Raciocínio Computacional. Anais do Simpósio Brasileiro de Educação em Computação, (pp. 255-262). Porto Alegre: SBC.

Neto, J. G. S., Fernandes, C. L., Nascimento, P. H. L. and Silva, M. H. (2016). Fatores que influenciam na escolha do curso superior por parte dos alunos do ensino médio: o professor exerce influência?. Anais III Congresso Nacional de Educação, Campina Grande: Realize Editora.

of University Women, A. A. and the Analysis Group, G.-L. (1994). Shortchanging Girls, Shortchanging America: Executive Summary: a Nationwide Poll that Assesses Self-esteem, Educational Experiences, Interest in Math and Science, and Career Aspirations of Girls and Boys Ages 9-15. American Association of University Women Educational Foundation.

Semis, L. and Monteiro, A. P. (2016). Mulheres enfrentam preconceito e isolamento em cursos de computação. Disponível em: $<$ https://www.programaria.org/preconceitomulher-cursos-computacao/>. Acesso em: 15 mar. 2021.

Sociedade Brasileira de Computação (2019). Educação Superior em Computação e Estatísticas. Disponível em: <https://www.sbc.org.br/documentos-dasbc/summary/133-estatisticas/1324-educacao-superior-em-computacao-estatisticas2019>. Acesso em: 14 mar. 2021. 